called 'back garden' fruit is usually left on the trees until almost, or quite, ripe, and therefore is far more attractive to, and more readily attacked by, the bats than the greener product. This probably accounts for far more general popular outcry against the animals than the actual economics of the situation justify. Still, looking at the matter merely from a business point of view, if the fox is not a menace to the large-scale commercial industry, there would seem to be little valid reason for any considerable expenditure of public money on its control.

Nevertheless, big losses occasionally occur, notably where soft fruits (figs, peaches, nectarines, etc.) are grown. The problem presented by these is much greater in New South Wales than in Queensland. Hence Mr. Ratcliffe has felt it necessary to discuss critically various methods which have been proposed for coping with the trouble. Control through direct destruction by shooting, he rules out as a physical and economic impossibility. Attack by contagious or infectious disease is probably hopeless. There is now such a mass of experience indicating the improbability that control can ever be brought about in this way that it seems not worth while even to initiate experiments. The use of poison gases in the camps is almost impracticable and, on good evidence, ineffective. Flame guns are useful to an extent, but objectionable in many respects, including that of the cruelty involved. As for the 'scalp bounty' system, as adopted by Queensland, Mr. Ratcliffe's condemnation of it is as emphatic as it is just. He shows that in one important area, if every penny of the money provided by the Pests Destruction Board as bounty were spent solely on foxes, at $3 d$. per animal, the total destruction would probably be less than 1 in 200 of the normal population. Even then, P. scapulatus, because the least intelligent species, would usually be the most heavily hit : as it is also the least troublesome, money spent on it would be sheer waste.

Apart, however, from attempts at mass control, much protection might be afforded in small localised areas by systematic use of deterrents and poisons by the fruit-growers, and recommendations are made for the encouragement of such practices.

It seems, then, that the economic significance of the bat trouble in Australia is not really very great; it has certainly been exaggerated. The fox is a nuisance rather than a pest, affecting chiefly the small home grower and not the commercial fruit industry. Possibly, as Mr. Rateliffe suggests, the reason for the prevalent exaggeration is partly psychological. The bat is nocturnal, noisy and smelly, and usually infested with parasites; in fact, decidedly detestable. It is no wonder, perhaps, that Mr. Ratcliffe found astonishing numbers of individuals prefacing their information regarding the foxes with a statement that they were "stinking, lousy brutes". Such an attitude is not without significance when one is seeking an unbiased assessment of the economic importance of a nuisance.

Be that as it may, the upshot of this very interesting inquiry should be to convince Australia that one, at least, of her pests is not so bad as it has been represented, and is not likely to become any worse. This will be some comfort to the Council for Scientific and Industrial Researeh, which finds decreasing funds and increasing responsibilities to be matters of grave embarrassment at the present time. A. C. D. R.

\title{
Young's Theory of Colour Vision.*
}

ALHOUGH Thomas Young is well known as the founder of a theory of colour vision, his contributions to the theory are limited to two or three short paragraphs, and there is no evidence that he himself attached much importance to them. He was the first who, starting from the well-known fact that there are three primary colours, sought for the explanation of this fact, not in the nature of light, but in the constitution of man. He wrote: "Now, as it is almost impossible to conceive each sensitive point of the retina to contain an infinite number of particles each capable of vibrating in perfect unison with every possible undulation, it becomes necessary to suppose the number limited, for instance, to the three primary colours-red, yellow, and blue .... and each sensitive filament of the nerve may consist of three portions, one for each principal colour." $\mathrm{He}$ afterwards took red, green, and violet as the three primary colours. His other statement regarding colour is in connexion with Dalton's colour-blindness, of which he says: "It is much more simple to suppose the absence or paralysis of those fibres of the retina which are calculated to perceive red".

Although the three component theory as developed by Clerk Maxwell, Helmholtz, and others accounted well for many of the facts of colour mixture, it had also to account for other phenomena of vision, such as visual acuity, the luminosity curve, hue discrimination, simultaneous and successive contrasts, and colour-blindness. Recent work by Hecht and others has succeeded in solving many of these problems.

The determination of the luminosity curve, which physicists still persist in calling the "visibility' curve, has been the subject of such accurate investiga-

* Substance of a paper read by Sir John H. Parsons, F.R.S., before the Optical Society on June 11. tion that it can now be regarded as one of the soundest scientific data in the whole realm of vision.

Dalton may be regarded as initiating the scientific study of colour vision, and later work by Seeback and Clerk Maxwell strongly supports the view expressed by Young that cases of colour-blindness are reduced forms of normal vision. On this theory, the neutral points of the spectrum as seen by protanopes and deuteranopes are excellently explained by the points of decussation of their two remaining curves.

The fact that yellow is psychologically as distinetive a colour as red, green, or violet, and physiologically shows no evidence of composite character, was long regarded as a strong argument against the trichromatic theory, until Hecht proved conclusively that the sensation of yellow could be experienced by fusing binocularly the sensations produced by appropriate red stimulation to one eye and green stimulation to the other.

Research since Young's day has done nothing to bridge the gap between the physiological and the psychological response, but considerable progress has been effected by Holmgren, Kohlrausch, Lucas, and Adrian in elucidating the physiological response itself. The results of these workers on the photochemical reaction of the visual purple, and the accompanying changes in electrical potential of the retinal structures, all tend to show that the fundamental phenomena of vision all manifest themselves in the retina.

Finally, the researches of Pieron, especially those on colour responses to black and white stimuli, and. those of Allen on induction effects as shown on the persistency curves resulting from previous stimulation of the retina by monochromatic light, all have a distinct confirmation bearing on Young's theory. 